\title{
A PROSPECTIVE STUDY OF DRUG UTILIZATION AND QUALITY OF LIFE IN PSORIASIS PATIENTS IN DERMATOLOGY DEPARTMENT OF A TERTIARY CARE TEACHING HOSPITAL
}

\section{Dr. Dhara Patel ${ }^{1}$, Dr. Ajita Pillai ${ }^{2}$, Dr. Sweta Nariya ${ }^{3}$, Dr. Neela Bhuptani ${ }^{4}$}

${ }^{1}$ MD Pharmacology, MBA, New York institute of technology, Vancouver, Canada.

${ }^{2}$ Associate Professor, Pharmacology Department, PDU Govt. Medical College, Rajkot

${ }^{3}$ Resident Doctor, Pharmacology Department, PDU Govt. Medical College, Rajkot

${ }^{4}$ Professor and Head, Dermatology Department, Venerology \& Leprosy (D.V.L.), PDU Govt. Medical College and Hospital, Rajkot

Article Info: Received 10 March 2021; Accepted 12 May 2021

DOI: https://doi.org/10.32553/jbpr.v10i3.860

Corresponding author: Dr. Sweta Nariya

Conflict of interest statement: No conflict of interest

\section{Abstract}

Purpose/aim: To assess the current prescription pattern, efficacy, tolerability and impact on Quality of life $(\mathrm{QoL})$ in psoriasis patients.

Material: An observational, prospective study of 18 months was carried out in a tertiary care teaching hospital. Newly diagnosed patients of psoriasis, aged $\geq 18$ years were included in the study. The demographic, clinical profile, psoriasis area severity index (PASI) and drug utilization were recorded. Follow up was done at 15 days interval for two and a half months. Patient's QoL was assessed using Psoriasis Disability Index (PDI).

Results: A total 100 patients were enrolled in the study. At the time of diagnosis, 43 patients had PASI score $\leq 10$ and 57 had $>10$. At the last follow up 96 patients had PASI sore $\leq 10$ and 4 had $>$ 10. Mean of QoL at the time of diagnosis was 10.43 and at the last follow up 6.1. Pre and posttreatment PASI score showed direct intermediate significant correlation with pre and post-treatment QoL score. Most frequently fixed drug combination(FDC)of steroid and keratolytic agent were prescribed followed by anti-histaminics, steroids, minerals, anti-microbial agents, emollients, vitamins, H2-blockers, immunosuppressants, and NSAIDS.WHO core indicators were used to analyse drugs prescribed.

Conclusions: In this study, the treatment of psoriasis is according to the "NICE" guideline. Patient's treatment adherence increased because of the QoL improvement. Thus, the QoL tools are important measure of patient satisfaction and treatment monitoring.

Keywords: Psoriasis area severity index, Psoriasis Disability Index, Quality of life, Drug Utilization in Psoriasis

\section{Introduction}

Psoriasis is a chronic inflammatory immune mediated proliferative skin disorder characterized by keratinocyte hyperproliferation, vascular endothelial proliferation, and inflammatory cell infiltration. The exact 
pathogenesis is not well understood, but it is known to be multifactorial, having both genetic and environmental influences. ${ }^{1}$ It affects $1-3 \%$ of world's population and characterized by sharply marginated scaly, erythematous plaques that develop in a relatively symmetrical distribution. ${ }^{2}$ Psoriasis is a serious condition associated with depression and anxiety. It affects patient's lifestyle, employment and social conditions. Thus, it has negative impact on patient's quality of life. Quantification of the impact of psoriasis on the Quality of life(QoL), along with clinical severity assessment, could provide a measure of the clinical efficacy of the dermatological therapies. ${ }^{3}$ Surprisingly, very few Indian study have looked into drug utilization pattern and impact on QoL in psoriasis patients. Hence, this study is aimed to assess the current prescription pattern, efficacy, tolerability, cosmetic acceptability of treatment and impact on QoL in psoriasis patients.

\section{Materials and Methods}

This was an observational, prospective study of 18 months duration from December 2015 to May 2017.It was carried out in tertiary care teaching hospital, Rajkot after taking permission from Institutional Ethics Committee (IEC) and head of the department of Dermatology and Venereology. Ethical approval was obtained from IEC on 30/11/2015(Letter no.-18689). Patients newly diagnosed as having psoriasis, aged above 18 years were included and patients already on treatment of psoriasis were excluded. Informed written consent of patients was taken before collection of the data.

The baseline data including demographic profile, clinical profile, psoriasis area severity index(PASI)score and drug utilization were recorded from patient's OPD case paper in preformed case record form (CRF). Follow up was done regularly at every 15 days interval for two and half months. During each follow up presenting complaints, drug utilization, PASI score were analysed. Patient's QoL was assessed at first visit and after $5^{\text {th }}$ follow up visit to evaluate the effect of treatment on it, by investigator by using psoriasis disability index (PDI) which was taken from Department of Dermatology at Cardiff University School of Medicine. Recorded data were analysed by using Microsoft excel 2013 and Graph pad prism 7. Chi square test was applied to see the significance between two variables. D'Agostino-Pearson Omibus normality test was used to check normality of PASI and QoL score. Wilcoxon matched pairs signed rank test was used to see the significance between pre and post treatment PASI and QoL score. Spearman correlation test was used to check the correlation between PASI score and QoL score. $\mathrm{P}$ value $<0.05$ was considered statistically significant.

\section{Results}

A total of 100 patients were included with follow up at 15 days interval for two and half months. Thus a total of 600 prescriptions were analysed. Out of 100 patients, 63 were males and 37 were females. Male to female ratio was 1.7:1.The Mean age of patients was $43.65 \pm$ 13.36 years. Based on Kupuswamy socioeconomic class scale, 81 patients were from middle socioeconomic class and 19 were from lower socioeconomic class. All the patients presented with multiple symptoms. The most common being itching, scaly plaque, powdery scales and burning sensation (Table 1). History of stress induced exacerbation of disease was present in 6 patients out of which 2 were males and 4 were females. History of sore throat was present in 40 patients, tonsillitis in 6 patients and one patient had both sore throat and tonsillitis. Positive history of smoking, alcohol consumption, and tobacco chewing was present in 29 patients. Family history was positive in 7 patients. Co-morbid conditions like hypertension, diabetes were present in 23 patients, for which the patients were treated with antihypertensives (amlodipine, atenolol, atorvastatin, losartan and metoprolol) and antidiabetics (metformin, glipizide). 
Table 1: Analysis of Presenting Symptoms in patients of psoriasis $(n=100)$

\begin{tabular}{|l|l|l|l|}
\hline Symptoms & Male & Female & Total \\
\hline Itching & 58 & 31 & 89 \\
\hline Scaly plaques & 45 & 26 & 71 \\
\hline Burning & 23 & 11 & 34 \\
\hline Redness & 2 & 4 & 6 \\
\hline Warmth & 1 & 2 & 3 \\
\hline Fever & 2 & 0 & 2 \\
\hline Pustules & 3 & 1 & 4 \\
\hline Nail pitting & 3 & 2 & 5 \\
\hline Powdery scale on scalp & 31 & 15 & 46 \\
\hline Powdery scale on palms and soles & 5 & 6 & 11 \\
\hline
\end{tabular}

Correlation between PASI score and QoL score:

At the time of diagnosis, out of 100 patients, 43 patients had PASI score $\leq 10$ and 57 had $>10$. At the last follow up 96 patients had PASI sore $\leq 10$ and only 4 had $>10$. Mean of QoL of all at the time of diagnosis was 10.43 and at the last follow up it was 6.1.Correlation between
PASI and QoL score was done using Spearman Rank correlation test. Pre and post-treatment PASI score showed direct intermediate significant correlation with pre and posttreatment QoL score with correlation (r) value 0.3726 , and 0.3902 respectively (Figure-2,3). $\mathrm{P}$ value is $<0.0001$.

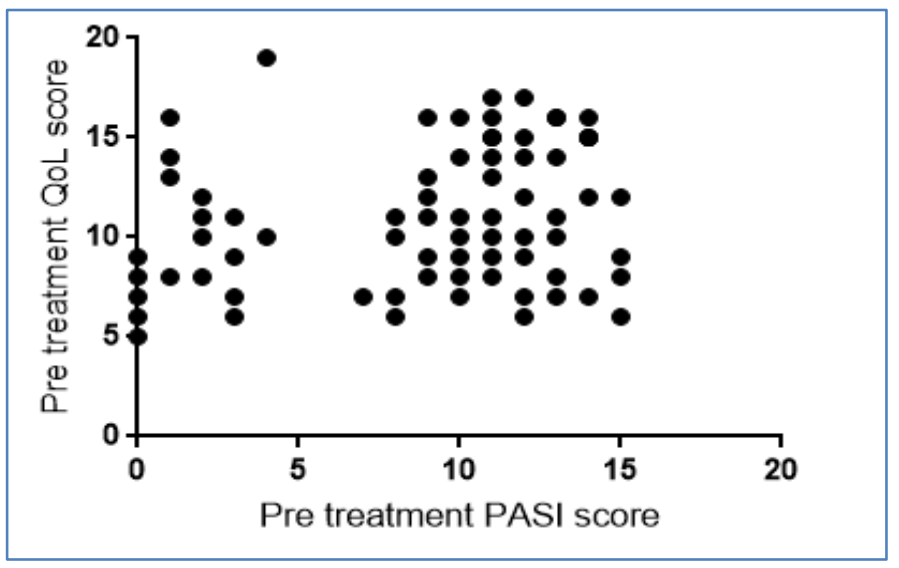

Figure 1: Correlation between pre-treatment PASI score and QoL score

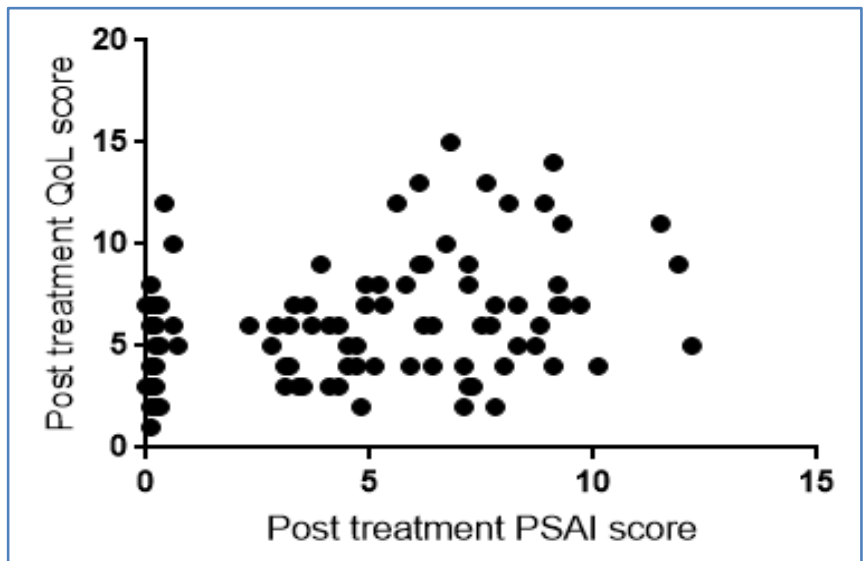

Figure 2: Correlation between post-treatment PASI score and QoL score 


\section{Analysis of drug utilization:}

All the patients were treated with topical and systemic therapy. As shown in Table-2, most frequently prescribed fixed dose combination was steroid and keratolytic agents.

Table 2: Drugs used in treatment of psoriasis

\begin{tabular}{|c|c|c|c|}
\hline $\begin{array}{l}\text { Sr. } \\
\text { No. }\end{array}$ & Group & Name of Drugs & $\begin{array}{l}\text { Number of } \\
\text { prescriptions } \\
(n=600), \%\end{array}$ \\
\hline \multirow[t]{3}{*}{1.} & \multirow[t]{3}{*}{ Antibiotics } & Azithromycin & $65(10.83 \%)$ \\
\hline & & Framycetin & $17(2.83 \%)$ \\
\hline & & Cefadroxyl & $4(0.66 \%)$ \\
\hline 2. & Non-antibiotic antimicrobial & Fluconazole (topical) & $374(62.33 \%)$ \\
\hline \multirow[t]{3}{*}{3.} & \multirow[t]{3}{*}{ Antihistaminics } & Chlorpheniramine & $326(54.33 \%)$ \\
\hline & & Cetirizine & $140(23.30 \%)$ \\
\hline & & Levocetirizine & $99(16.5 \%)$ \\
\hline \multirow[t]{2}{*}{4.} & \multirow[t]{2}{*}{ Steroids } & Betamethasone(topical) & $409(68.17 \%)$ \\
\hline & & Clobestasol propionate(topical) & $126(21 \%)$ \\
\hline 5. & Immunosuppressant & Methotrexate & $48(8 \%)$ \\
\hline 6. & Mineral & Calcium & $508(84.67 \%)$ \\
\hline \multirow[t]{2}{*}{7.} & \multirow[t]{2}{*}{ Vitamins } & Folic acid & $140(23.33 \%)$ \\
\hline & & Vitamin A & $21(3.5 \%)$ \\
\hline 8. & $\mathbf{H}_{2}$-blocker & Famotidine & $51(8.5 \%)$ \\
\hline 9. & NSAIDs & Ibuprofen & $6(1 \%)$ \\
\hline 10. & Emollient & Liquid paraffin (topical) & $311(51.83 \%)$ \\
\hline \multirow[t]{4}{*}{11.} & \multirow[t]{4}{*}{ Fixed dose combinations } & Salicylic acid + Benzoic acid (topical) & $284(47.33 \%)$ \\
\hline & & $\begin{array}{l}\text { Clobestasol propionate }+ \text { Salicylic acid } \\
\text { (topical) }\end{array}$ & $282(47 \%)$ \\
\hline & & Betamethasone + Salicylic acid (topical) & $12(2 \%)$ \\
\hline & & Ketoconazole + Zinc(topical) & $1(0.17 \%)$ \\
\hline
\end{tabular}

Table 3: Analysis of prescriptions according to WHO core indicators

\begin{tabular}{|l|l|l|}
\hline $\begin{array}{l}\text { Sr. } \\
\text { No. }\end{array}$ & WHO core indicators & $\begin{array}{l}\text { Number } \\
\text { /percentage }\end{array}$ \\
\hline 1. & Average number of drugs prescribed per encounter & 5.37 \\
\hline 2. & Percentage of drug prescribed by generic name & $100 \%$ \\
\hline 3. & Percentage of encounter with antibiotics & $14.33 \%$ \\
\hline 4. & Percentage of prescription containing fixed dose combination & $17.95 \%$ \\
\hline 5. & Percentage of drug prescribed from WHO list of Essential Medicines (2015) & $48.76 \%$ \\
\hline 6. & $\begin{array}{l}\text { Percentage of drug prescribed from National List of Essential Medicines } \\
(2011)\end{array}$ & $65.29 \%$ \\
\hline
\end{tabular}

\section{Adverse drug reaction profile:}

Adverse drug reactions (ADRs) caused by drugs used in the treatment of psoriasis were staining, skin irritation, nausea, and skin dryness. Causality assessment was done by WHO causality scale which indicated that all ADRs were "possible". Severity and preventability of ADRs were assessed with Modified Hartwig and Siegel scale and Schumock and Thornton preventability scale respectively. Out of all ADRs, 23 were of "level 3 severity" and 6 were of "level 2 severity". All the ADRs were "not preventable'(Table 
Table 4: Analysis of Adverse drug reactions

\begin{tabular}{|l|l|l|l|}
\hline $\begin{array}{l}\text { Adverse drug } \\
\text { reactions }\end{array}$ & $\begin{array}{l}\text { Number of patients } \\
\mathbf{N = 2 9}\end{array}$ & Suspected drugs & $\begin{array}{l}\text { WHO } \\
\text { causality }\end{array}$ \\
\hline Staining & 6 & Glucocorticoids & Possible \\
\hline Skin irritation & 11 & Lotion Clobestasol propionate + Salisylic acid & Possible \\
\hline Nausea & 5 & Methotrexate & Possible \\
\hline Skin dryness & 7 & Lotion Clobestasol propionate + Salisylic acid & Possible \\
\hline
\end{tabular}

\section{Discussion}

Psoriasis is a lifelong, chronic, immune mediated, inflammatory skin disease. There is no cure for psoriasis, treatment is only palliative and symptomatic. In our study, male patients slightly outnumbered female patients which is similar to other Indian studies conducted by Ramani YR et al in Odisa, Meenu Vijayan et al in Kerala and V. V. Karamata et al in Ahmedabad. ${ }^{6,7,12}$ It may be because these studies are mostly hospital based and not population based. In our study, the mean and standard deviation (SD) of age of psoriasis patients was $43.65 \pm 13.36$.Majority of study subjects $(29 \%)$ were in the age group of 51-60 years and $23 \%$ were in age group of $31-40$ years, showing bimodal pattern of age distribution. The results from the systematic review showed that psoriasis is less common in children than adults. In an Indian study done by Raghunandan $\mathrm{R}$ et al in Bangalore, mean and standard deviation (SD) of age and age group of psoriasis patients, were $42.2 \pm 13.9$ years and 18-60 years, respectively which is comparable to our study. ${ }^{8}$

In our study, according to Kupuswamy socioeconomic class scale, majority of patients $(81 \%)$ were from middle socioeconomic class, probably reflecting socioeconomic strata of patients preferring tertiary care teaching hospital. Similar findings were observed in study done by Raghunandan $\mathrm{R}$ et al in Bangalore which reported $90.90 \%$ of patients were from middle socioeconomic class. ${ }^{8}$

The genetic basis of psoriasis has been appreciated for nearly 100 years. In our study $7 \%$ patients had positive family history. In other studies done by Meenu Vijayan et al in Kerala, Barot PA et al in Gujarat and V. V. Karamata et al in Ahmedabad, family history was positive in $7 \%, 8.3 \%$ and $22 \%$ patients, respectively. ${ }^{7,9,12}$ Despite lower incidence, it indicates possible roll of genetic factors in the etiology of psoriasis.

Heavy smoking and high rates of alcohol intake are known triggering or exacerbating factors in psoriasis. Smoking more than 20 cigarettes per day increased two fold risk of severe psoriasis. Alcohol shows dangerous interactions with some antipsoriatic drugs like methotrexate. ${ }^{10,11}$ In our study, $29 \%$ patients had positive history of smoking, alcohol consumption, and tobacco chewing. In another study conducted by Karamata VV et al in Ahmedabad, Gujarat, $20.17 \%$ and $15.79 \%$ patients had positive smoking and alcohol history, respectively. ${ }^{8,12}$

Upper respiratory tract infections especially those caused by streptococci may cause flareup of existing psoriasis or may precipitate an attack of acute guttate psoriasis. ${ }^{13}$ Role of bacterial superantigens in the pathogenesis of variant psoriasis has been postulated. ${ }^{14}$ In our study, 47 patients had history of sore throat, and tonsillitis. Qazi M et al in Kashmir Valley reported history of sore throat was present in 179 patients out of 1000 patients. $^{15}$

In our study, all patients presented with different types of symptoms at the time of diagnosis of which commonest was itching. Other studies done by, Barot PA et al, Kaur I et al and Bedi TR et al noted itching to be a significant complaint in, $66.67 \%, 65 \%, 81 \%$ of patients, respectively. ${ }^{9,16,17}$

In our study Co-morbid conditions like hypertension, diabetes was seen. The exact mechanism underlying these associations is unknown, but it may be due to alterations to the renin-angiotensin system, elevated endothelin-1 level, and increased oxidative stress. ${ }^{18}$ Th- 1 
cytokines that are overproduced in psoriasis are thought to promote insulin resistance as well. ${ }^{18}$

The PASI is the most widely used measurement tool for psoriasis. It combines the assessment of the severity of lesions and the area affected into a "single score" in the range of 0 (no disease) to 72 (maximal disease). ${ }^{10}$ In our study baseline PASI score was measured and it ranged from 0.3 to 15.7 . There was significant improvement seen in patient's PASI score after $2 \frac{1 / 2}{2}$ months of treatment. Thus, PASI was used to assess efficacy of given treatment in psoriasis. Studies done by Ramani YR et al and Raghunandan R et al also showed significant improvement in PASI after 8 weeks and 12 weeks of treatment respectively. ${ }^{6,8}$

In our study, we used psoriasis disability index (PDI) to assess QoL of patients. The PDI is calculated by summing the score of each of the 15 questions after four months of treatment. Categorical scores were given to each question according to the severity in which score 3 means "very much" (severe), score 2 means "a lot" (moderate), score 1 means "very little" (mild), and score 0 means "not at all" (unaffected) and the resulting score ranged from 0 to 45 . The higher the score, the more QoL is impaired. PDI can also be analysed under five subsets, namely, daily activities, work, personal relationship, leisure and treatment. In our study, percentage of patients affected in particular subset of PDI was measured. Majority of patient's QoL was affected in daily activities (100\%) followed by leisure $(83 \%)$, work $(75 \%)$, treatment $(52 \%)$ and personal relationships (13\%). These findings were in accordance with the study done by Manjula VD et al in Kottayam which reported the QoL was most affected in "daily activities" (90.6\%) followed by "work" $(84.4 \%) .{ }^{19}$ In our study, significant improvement was seen in patient's quality of life after 10 weeks of therapy. Correlation between pre-treatment and post-treatment PASI score and QoL were done using Spearman Rank correlation test which shows direct intermediate significant correlation between pre and post-treatment PASI score and QoL score with correlation value (r)-0.3726, and 0.3902 respectively. Similar findings were seen in studies conducted by Gelfand JM et al (correlation value: 0.50), Rakhesh SV et al in Pondicherry (correlation value: 0.866) which reported intermediate and strong direct significant correlation between PASI and QoL score. $^{20,21}$

WHO core indicators were used to analyse drug utilization. The average number of drugs prescribed per prescription was 5.37 which is higher than that reported in previous studies done by Barot PA et al in Gujarat (5.05) and Ramani YR et al in Kerala (3.46). ${ }^{6,9}$ It is also more than the WHO recommendation $(<3 /$ prescription) indicating a trend of polypharmacy. ${ }^{23}$ Polypharmacy is known to cause unnecessary adverse reactions, drug interactions, complications, medication nonadherence, various medication errors, and increased cost of therapy. In our study, $100 \%$ drugs were prescribed by generic names which may reduce overall expenditure on drugs and avoiding medication error. According to NICE guideline, treatment of psoriasis varies in all patients depending on the type of psoriasis, severity and body sites involved. First line therapy describes traditional topical therapies like topical steroids, emollients and keratolytics. Second line therapy includes phototherapy and third line therapy includes systemic immunosuppressants. Anti-microbial agents are prescribed at the time of acute exacerbation and infection. Anti-histaminics, $\mathrm{H}_{2}$ blockers, vitamins, minerals are used as adjuvant drugs. ${ }^{22}$

\section{Conclusion}

In our study, the treatment of psoriasis is according to the NICE guideline. Patient's adherence to the treatment increased because of the improvement in the Quality of Life (QoL). Thus, the QoL tools are important measure of patient satisfaction and treatment monitoring in the developing world.

\section{References}

1. Rauf S, Khan UA, Azer R. Clinical presentation of psoriasis in a tertiary care 
hospital of Khyber Pakhtunkhwa. J Med Sci 2012;20:87-9.

2. Kuchekar AB, Pujari RR, Kuchekar SB, Dhole SN, Mule PM. Psoriasis: A comprehensive review. Int $\mathrm{J}$ of Pharm Life Sci 2011 June;2(6):857-77.

3. Bamber, Petrina Nicole "Quality of life for patients with psoriasis: more than skin deep." (2009). Master's and doctoral projects.272. Available at: http://www.utdr.utoledo.edu/graduateprojects/272.

4. Pairisi R, Symmons D, Griffiths C, Ashcroft DM. Global epidemiology of psoriasis: A systemic review of incidence and prevalence. Journal of investigative Dermatology 2013;133:377-85.

5. Schon MP, Boehncke WH. Psoriasis: review article. N ENGL J MED 2005 May 5;352:1899-1912.

6. Ramani YR, Panigrahy B, Mishra S, Singh BTPS. A study of treatment modalities in psoriasis in dermatology outpatient department of a tertiary care teaching hospital. Indian Journal of Basic and Applied Medical Research 2016 June;5(3):p. 116-22.

7. Vijayan M, Shini VK, Emmanuel J, Dharmaratnam AD. Prevalence, clinical profile and prescribing pattern of psoriasis in a tertiary care referral hospital. Int J Pharm Techno 2010 Dec;1241-52.

8. Raghunandan R, Pundarikaksha HP, Gopal MG. Pattern of drug use in a tertiary care hospital: a prospective study. International Journal of Basic and Clinical pharmacology 2014 JulyAugust;3(4):p. 611-18.

9. Barot PA, Brahmbhatt NY, Malhotra SD, Patel VJ. Study of drug prescribing patterns in psoriasis and assessment of rationality using SIGN and NICE guideline at a tertiary care teaching hospital. International Journal of Pharmaceutical science and Research 2016;7(7):3073-79.
10. Psoriasis. Sacchidanand S. IAVDL Textbook of dermatology. $4^{\text {th }}$ ed. Bhalani book depot; 2016. P. 1014-89.

11. Gudjonsson JE, Elder JT. Psoriasis. Wolff K, Goldsmith LA, Katz SI, Gilchrest BA, Paller AS, Leffell DJ, editors. Fitzpatrick's Dermatology in General Medicine. $8^{\text {th }}$ ed. New York: Mc Graw Hill Medical; 2011. P. 169-93.

12. Karamata VV, Gandhi AM, Patel PP, Sutaria A, Desai MK. A study of the use of drugs in patients suffering from psoriasis and their impact on quality of life. Indian J Pharmacol 2017 JanFeb;49(1);84-88.

13. Sjoqvist F, Birkett D. Drug utilization. Introduction to Drug Utilization Research. WHO office of publications 2003; 76-84.

14. Maciejewska-Radomska A, Szczerkowska-Dobosz A, Rebata K, Wysocka J, Roszkiewicz J, Szczerkowska $\mathrm{Z}$, et al. Frequency of streptococcal upper respiratory tract infection and HLA$\mathrm{Cw}^{*} 06$ allele in 70 patients with guttate psoriasis from northern Poland. PostepDermAlergol 2015;XXXII(6):45558.

15. Massod Q, Hassan I, Sammen F, Khan D, Majid I, Guruchara S et al. Psoriasis in Kashmir valley: A clinic-epidemiological study. J K Science 2011 AprilJune;13(2):80-83.

16. Kaur I, Handa S, Kumar B: Natural history of psoriasis: a study from the Indian subcontinent. J Dermatol 1997;24:230-4.

17. Bedi TR: Clinical profile of psoriasis in North India. Indian J Dermatol Venereol Leprol 1995; 61:202-05.

18. Ni C, Chiu MW. Psoriasis and comorbidities: links and risks. Clinical, Cosmetic and Investigational Dermatology 2014 April 17;7:119-132.

19. Manjula VD, Shrikiran S, Saril PS, Sreekanth MP. A study of psoriasis and quality of life in tertiary care teaching hospital of kottayam, Kerala. Indian $\mathbf{J}$ Dermatol 2011 Jul-Aug;56(4):403-6. 
20. Rakhesh SV, D'Souza M, Sahai A. Quality of life in psoriasis: A study from south India. Indian J Dermatol Venereol Leprol 2008;74:600-6.

21. Gelfand JM, Feldman SR, Stern RS, Thomas J, Rolstad T, Marqolis DJ. Determinants of quality of life in patients with psoriasis: a study from the US population. J Am Acad Dermatol 2004 Nov;51(5):704-8.

22. NICE (National institute for health and clinical excellence) clinical guideline 153, The assessment and management of psoriasis, October 2012. Available at URL:http//www.guidance.nice.org.uk/cg 153.

23. EL Mauhali AA. WHO/INRUD drug prescripting indicators at primary health care centres in eastern province, Saudi Arabia. Eastern Mediterranean Health Journal 2012 Jan 11;18(11):1091-96.
24. World Health Organization. How to investigate drug use in health facilities. Selected drug use indicators. WHO/DAP/93.1. WHO, Geneva, 1993.

25. Goossens H. Antibiotic consumption and link to resistance. Clin Microbial Infect 2009;15:12-5.

26. Connor J, Rafter N, Rodgers A. Do fixeddose combination pills or unit-of-use packaging improve adherence? A systemic review. Bull World Health Organ. 2004;82:935-9.

27. $19^{\mathrm{th}}$ WHO model list of essential medicines-World Health Organization. Available at. URL:http//www.who.int/ medicines/publications/essentialmedicine s/EML2015_8-may-15.pdf.

28. National list of essential medicine (NLEM) 2015. Available at URL:cdsco.nic.in/WriteReadData/NLEM -2015/NLEM,\%202015.pdf 